\title{
АПРОБАЦИЯ КРАТКОЙ ВЕРСИИ ОПРОСНИКА МЕТАКОГНИТИВНЫХ УБЕЖДЕНИЙ НА РУССКОЯЗЫЧНОЙ ВЫБОРКЕ
}

\author{
Н.А. СИРОТА \\ А.В. ЯЛТОНСКАЯ
}

\begin{abstract}
"Московский государственный медико-стоматологиеский университет имени А.И. Евдокимова Министерства здравоохранения Российской Федерации, 127473, Россия, Москва, ул. Делегатская, ว. $20, \mathrm{cmp} .1$

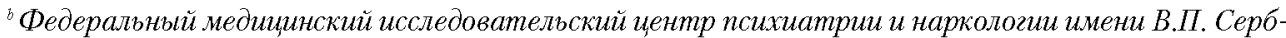
ского, 119002, Россия, Москва, Малый Могильцевский пер., 2.3
\end{abstract}

\section{Резюме}

Согласно метакогнитивной теории А. Уэллса, тревожные расстройства и депрессия обусловлены наличием дисфункциональных метакогнитивных убеждений. По данной концепции выделяют пять ключевых метакогнитивных факторов, обуславливающих развитие аффективных расстройств: позитивные убеждения, касающиеся беспокойства; негативные убеждения по поводу неуправляемости и опасности беспокойства; контроль мыслей; внимание к собственным мыслительным процессам; когнитивное недоверие. Активизация данных метакогнитивных убеждений приводит к развитию и поддержанию стереотипных стилей мышления, таких, как беспокойство и руминирование, а также к постоянному мониторингу угрозы и попыткам подавить нежелательные мысли. Краткая версия опросника метакогнитивных убеждений позволяет измерять индивидуальные различия в выборе дисфункциональных метакогнитивных убеждений. Данная статья посвящена описанию разработки и апробации краткой версии опросника метакогнитивных убеждений на русскоязычной выборке. В исследовании приняли участие 500 человек: 200 студентов, обучающихся в Московском государственном медико-стоматологическом университете имени А.И. Евдокимова, 100 респондентов было обследовано с помощью интернет-технологий (электронных Гугл форм), 200 женщин с онкологическими заболеваниями репродуктивной системы. Результаты показали, что краткая версия опросника метакогнитивных убеждений полностью соответствует англоязычной версии в отношении надежности-согласованности и внутренней структуры пунктов, а также характеризуется высокой ретестовой надежностью. Внешняя валидность методики подтверждается значимыми связями дисфункциональных метакогнитивных факторов с выраженностью тревожно-депрессивных переживаний и выбором малоадаптивных стратегий когнитивной регуляции эмоций. По результатам регрессионного анализа было выявлено, что такие метакогнитивные факторы, как негативные убеждения, связанные с 
неуправляемостью и опасностью беспокойства, внимательность к собственным мыслительным процессам, а также позитивные убеждения, касающиеся беспокойства, вносят самостоятельный вклад в развитие тревоги. Показано, что в развитие депрессивных переживаний вносят вклад такие метакогнитивные факторы, как негативные убеждения, связанные с неуправляемостыю и опасностью беспокойства, когнитивная несостоятельность, внимательность к собственным мыслительным процессам.

Ключевые слова: опросник метакогнитивных убеждений, метакогнитивные убеждения, психометрика; позитивные убеждения, касающиеся беспокойства; негативные убеждения в неуправляемости и опасности беспокойства, контроль мыслей, когнитивное недоверие.

В современной когнитивной психологии все большее внимание уделяется метапознанию как отличительной особенности познавательной активности человека, направленной на собственную психику. Термин «метапознание» был введен и описан Дж. Флэйвеллом в контексте возрастной и педагогической психологии (Flavell, 1979). Исследователь определил метапознание как «познание о когнитивных явлениях», или «мышление о мышлении». В более поздних работах метапознание определяют как «осведомленность о собственном мышлении и знание о способах управления им» (Kuhn, Dean, 2004). Метапознание обычно определяют как познание второго порядка, т.е. мысли о мыслях, знание о знании или рефлексия и критичность к собственному опыту (Papaleontiou-Louca, 2003). Как отмечает A.В. Карпов, «метакогнитивные процессы двуедины по своей психологической природе: являясь когнитивными по механизмам, они регулятивны по направленности, т.е. по функциональному предназначению» (Карпов, 2004).

Концепция метапознания активно развивалась в течение последнего десятилетия, интегрируя в себя различные психологические феномены, такие как знание о своих эмоциях и об эмоциях других людей (Papaleontiou-Louca, 2003). Метапознание как концептуальный подход тесно связано с другим более широким подходом, который в современной литературе получил название «теория психического» (Flavell, 1999). Однако исследователи метапознания, в первую очередь, сосредоточились на изучении преимуществ и недостатков в рефлексии собственных мыслей и состояний, тогда как в рамках теории психического акцент в большей степени сделан на способности рефлексировать и делать выводы о мыслях и чувствах другого человека (AlHilawani et al., 2002).

Метапознание включает в себя две типа психической активности: метакогнитивное знание и метакогнитивную регуляцию. Метакогнитивное знание знание или понимание когнитивных процессов; метакогнитивная регуляция - способность человека управлять собственными когнитивными процессами при решении проблем (Brown, 1987). Метакогнитивное знание включает в себя понимание индивидом сильных и слабых сторон своих когнитивных процессов, тогда как метакогнитивная регуляция предполагает использование различных механизмов саморегуляции: планирование, мониторинг, контроль и самооценку эффективности решения задач (Cross, Paris, 1988). 
В отечественной клинической психологии исследования метакогниций приобрели особую актуальность по отношению к ситуации болезни, где произвольная регуляция деятельности субъекта подчинена адаптационным задачам, что приводит к актуализации особой познавательной активности познания себя в болезни. Исследования «инсайта болезни» - интегративного переживания в отношении симптомов и причин болезни - показали, что самопознание, формирующееся как результат осознания себя в болезни, начинает выполнять регулирующую функцию, определяя мотивацию лечения, готовность к лечению и поведение больного (Тхостов и др., 2007).

Исследования с использованием опросников, направленных на изучение метакогнитивных убеждений, показали, что негативные метакогнитивные убеждения вносят существенный вклад в развитие генерализованного тревожного расстройства (Wells, Carter, 2001), обсессивно-компульсивного расстройства (Wells, Papageorgiou, 1998) и депрессии (Papageorgiou, Wells, 2001).

Понятие метапознания все чаще применяется к психотерапии, на основе накопленных экспериментальных исследований было разработано направление когнитивной психотерапии, получившее название «метакогнитивная терапия». Метакогнитивная терапия принципиально отличается от многих других традиционных психотерапевтических подходов. Данный подход предполагает фокусировку на процессах человеческого мышления, а не на содержании мыслей (Fisher, Wells, 2009). Иными словами, то, каким образом человек думает, и то, как он управляет своим поведением, является особенно важным для метакогнитивного терапевта. Все расстройства объединены активацией дисфункциональных паттернов мышления и внимания, которые составляют «когнитивный синдром внимания» (Wells, 2000). Когнитивный синдром внимания - это паттерн стратегических процессов активности, автоматически запускаемый метакогнитивным знанием, хранящимся в памяти. Хотя этот процесс часто инициирован непроизвольными интрузивными мыслями вследствие автоматической переработки информации, тем не менее для реализации этого процесса требуется доступ к метакогнитивному планированию (образу действий) - программе управления когнициями и действиями. Эти виды планирования не доступны в вербальной форме, они проявляются как метакогнитивные убеждения относительно когнитивных стилей (Wells, 2002). Иными словами, когнитивный синдром внимания заключается в ригидной самофокусировке внимания на стереотипном стиле мышления (беспокойство и руминирование), мониторинге опасности (угрозы), а также подавлении мыслей.

Сторонники метакогнитивной теории определяют беспокойство как «цепочку негативно окрашенных мыслей и образов, относительно слабо контролируемую и представляющую собой попытку решить проблему, исход которой в значительной степени неопределен, но с некоторой вероятностью может быть негативным» (Borkovec, 1985), тогда как руминирование - «пассивные, повторяющие мысли о симптомах, их возможных причинах и последствиях» (Nolen-Hoeskema, 2004). Основой для активизации поддержания данных форм мышления, с точки зрения метакогнитивных терапевтов, выступают метакогнитивные убеждения. 
Понятие метакогнитивных процессов открывает возможность интегративной характеристики регуляторных функций человека с учетом различных субъективных критериев оценки ситуации, что обусловливает интерес исследователей к данной проблематике.

В рамках метакогнитивной терапии для оценки когнитивного синдрома внимания был разработан опросник метакогнитивных убеждений. Данная методика включала в себя 65 пунктов, направленных на оценку различных аспектов метапознания. Факторный анализ пунктов опросника позволил выделить пять коррелирующих между собой, но концептуально различных факторов, которые оценивают три области: позитивные и негативные метакогнитивные убеждения, метакогнитивный мониторинг и когнитивную уверенность. По результатам факторного анализа выделены следующие субшкалы: 1) позитивные убеждения, касающиеся беспокойства; 2) негативные убеждения в неуправляемости и опасности беспокойства; 3) когнитивное доверие (уверенность в собственной памяти и внимании); 4) контроль мыслей; 5) внимание к собственным мыслительным процессам. Внутренняя согласованность для пяти факторов варьировалась в диапазоне от 0,72 до 0,89 (Cartwright-Hatton, Wells, 1997).

В дальнейшем для скрининговой оценки динамики психотерапевтических интервенций и снижения времени, затраченного на диагностику, была разработана краткая версия опросника метакогнитивных убеждений. Полученные в ходе разработки методики психометрические характеристики соответствуют исходной версии (65 пунктов) (Wells, Cartwright-Hatton, 2004).

Несмотря на то что метакогнитивные механизмы вносят явный вклад в развитие психических расстройств, их изучение в отечественной клинической психологии носит фрагментарный характер (Рассказова, Плужников, 2013). Это связано с ограниченным количеством методик, позволяющих исследовать различные аспекты метапознания, в отечественной клинической психологии.

Целью данной статьи является апробация краткой версии опросника метакогнитивных убеждений А. Уэллса и С. Картрайт-Хаттон на русскоязычной выборке.

\section{Выборка и схема исследования}

В исследовании приняли участие 500 человек $(\mathrm{n}=500)$. Исследование проводилось на следующих выборках:

- 200 студентов, обучающихся в Московском государственном медикостоматологическом университете имени А.И. Евдокимова. Средний возраст составил $20.69 \pm 3.56$. Из них 100 студентов, обучающихся на лечебном факультете с 3-го по 5-й курс (n = 100); 100 студентов, обучающихся на факультете клинической психологии с 3-го по 4-й курс $(n=100)$. Было обследовано 98 респондентов мужского пола (n = 98) и 102 респондента женского пола $(n=102)$. На момент обследования состояли в браке 54 студента $(27 \%)$, 67 состояли в отношениях $(33,5 \%)$, не имеющие отношений и не состоящие в браке - 79 обследованных $(39,5 \%)$. 
- 100 респондентов были обследованы с помощью интернет-технологий (электронные Гугл-формы). Средний возраст обследованных составил $32.61 \pm$ 7.06. Среди обследованных 65 респондентов с высшим образованием (65\%), 30 испытуемых со средним специальным образованием (30\%), 5 испытуемых со средним образованием (5\%). Были обследованы 63 респондента женского пола (63\%) и 37 респондентов мужского пола (37\%). На момент обследования состояли в браке 68 обследованных (68\%), в отношениях 18 (18\%), не имели отношений и не состояли в браке - 14 (14\%). По данным самоотчета, обследованные не имели психических, неврологических, а также тяжелых соматических заболеваний на момент обследования.

- 200 женщин со злокачественными онкологическими заболеваниями репродуктивной системы. Средний возраст составил 54.66 \pm 6.86. Обследовано 70 женщин, больных раком молочной железы (шифр по МКБ-10 - С50); из них на начальных стадиях заболевания обследованы 30 больных, на поздних стадиях 40 пациенток; 60 женшин, страдаюших раком тела матки (шифр по МКБ-10 - C54), из них на начальных стадиях заболевания обследованы 55 пациенток, на поздних стадиях - 5 больных; 70 женшин, больных раком яичников (шифр по МКБ-10 - С56), из них на начальных стадиях обследованы 29 больных, на поздних стадиях обследована 41 пациентка. Все обследованные пациентки проходили стационарное и амбулаторное лечение в онкологическом центре Центральной клинической больницы № 2 имени Н.А. Семашко ОАО «РЖД» в г. Москва.

Процедура разработки краткой версии опросника метакогнитивных убеждений на русскоязычной выборке состояла из следующих этапов.

1. Первичная адаптация опросника метакогнитивных убеждений А. Уэллса и С. Картрайт-Хаттон в соответствии с протоколом ВОЗ, включающим прямой и обратный перевод текста опросника, оценка восприятия текста вопросов в фокус-группах, проведение экспертной оценки результатов с привлечением не менее трех специалистов в области психического здоровья. В результате данной процедуры был подготовлен текст опросника на русском языке, состоящий из 30 пунктов, оцениваемых по шкале Лайкерта (1 - не согласен, 4 - полностью согласен).

2. Сбор данных для оценки психометрических показателей опросника.

3. Оценка распределения пунктов, надежности и внутренней структуры методики. На данном этапе рассчитывались показатели описательной статистики, выявлялись надежность-согласованность пунктов, ретестовая надежность (повторное тестирование подвыборки испытуемых) и структура шкал методики (на основе эксплораторного факторного анализа и конфирматорного факторного анализа).

4. Выявление связи социально-демографических характеристик (пол, возраст, семейное положение), а также клинико-анамнестических характеристик (в подвыборке больных, страдающих онкологическими заболеваниями репродуктивной системы) с краткой версией опросника метакогнитивных убеждений.

5. Оценка внешней валидности. С целью установления внешней валидности дополнительно использовались следующие методики: 
5.1. Госпитальная шкала тревоги и депрессии. Данная методика была разработана в 1983 г. для оценки симптомов депрессии и тревожных состояний у больных, находящихся на лечении в медицинских учреждениях различного типа. Шкала широко применяется для исследования тревожных и депрессивных переживаний в общей популяции (Zigmond, Snaith, 1983). В 1993 г. адаптирована на русскоязычной выборке М.Ю. Дробижевым. В концепции А. Уэллса дисфункциональные метакогнитивные убеждения выступают как имплицитные механизмы, запускающие тревожные или депрессивные переживания. В связи с этим для оценки соотношения данных переменных с метакогнитивными уб́ежениями в русскоязычной популяции нами была использована шкала тревоги и депрессии.

5.2. Опросник когнитивной регуляции эмоций. Для исследования когнитивных стратегий регуляции эмоций использовался опросник когнитивной регуляции эмоций (Garnefski et al., 2001), позволяющий исследовать 9 стратегий: «Самообвинение», «Принятие», «Руминации» «Позитивное мышление», «Планирование», «Положительный пересмотр», «Помещение в перспективу», «Катастрофизация», «Обвинение других». Данный опросник адаптирован на русскоязычной выборке И.В. Плужниковым (Плужников, 2010). Согласно результатам зарубежных исследований, дисфункциональные метакогнитивные убеждения связаны с особенностями обработки эмоциональной информации, ригидными правилами в отношении эмоций, а также со стратегиями, отражающими стереотипные формы регуляции, например, руминации, катастрофизация и обвинение других. Это обуславливает наш выбор: для проверки связи русскоязычной версии опросника со стереотипными формами регуляции нами был использован опросник когнитивной регуляции эмоций.

6. Оценка конструктной валидности методики. В соответствии с моделью А. Уэллса функция дисфункциональных метакогнитивных убеждений заключается в активизации и поддержании тревожно-депрессивных переживаний, повышении эмоционального дистресса. Мы предположили, что различные метакогнитивные факторы вносят самостоятельный вклад в развитие тревоги и депрессии.

Обработка данных проводилась в программе STATISTICA Enterprise for Windows, Version 10.0, Copyright (C) Stat Soft Inc, 2011.

\section{Результаты и обсуждение}

\section{Особенности распределения баллов по икалам опросника}

Отвечая на пункты опросника, испытуемые использовали всю шкалу ответов (от 1 до 4 баллов). Распределения шкал и общего балла по шкале отличаются от нормального по критерию Колмогорова-Смирнова $(p<0.02)$. Анализ особенностей распределения (асимметрия и эксцесс) позволяет выявить отрицательный эксцесс: испытуемые несколько чаще, чем ожидается, набирают крайние баллы по методике. Иными словами, опросник характеризуется 
сдвигами распределения в сторону бо́льших или меньших значений, что может демонстрировать уязвимость формулировок в отношении социальной желательности.

Проведенный дескриптивный анализ представлен в таблице 1.

\section{Факторная структура методики}

Согласно концепции А. Уэллса, опросник включает в себя пять метакогнитивных факторов: позитивные убеждения, касающиеся беспокойства (убеждения, отражающие веру в то, что более частое беспокойство поможет избежать проблем и справиться с трудностями); негативные убеждения, связанные с неуправляемостью и опасностью беспокойства (убеждения относительно невозможности контроля и телесной, психологической или социальной опасностью беспокойства); когнитивная несостоятельность (негативные убеждения в отношении собственной мнестической деятельности); контроль мыслей (убежденность в том, что если не контролировать свои мысли, то может случиться что-то плохое); внимательность к собственным мыслительным процессам (шкала, отражающая выраженность когнитивного синдрома внимания - тенденции фокусировать свое внимание на собственных мыслях, думать о них).

Соответствие русскоязычной версии методики оригинальной факторной структуре проверялось при помощи конфирматорного факторного анализа.

При создании модели конфирматорного факторного анализа каждый пункт опросника был изначально отнесен к соответствующему фактору (таблице 2).

По результатам конфирматорного факторного анализа были получены следующие результаты:

Таблица 1

Дескриптивный анализ распределения баллов по шкалам опросника

\begin{tabular}{|l|c|c|c|}
\hline \multicolumn{1}{|c|}{ Параметры оценки } & Асимметрия & Эксцесс & $\begin{array}{c}\text { Критерий } \\
\text { Колмогорова-Смирнова }\end{array}$ \\
\hline $\begin{array}{l}\text { Позитивные убеждения, } \\
\text { касающиеся беспокойства }\end{array}$ & 1.037 & 0.413 & $p<0.01$ \\
\hline $\begin{array}{l}\text { Негативные убеждения, } \\
\text { связанные с неуправляемостью } \\
\text { и опасностью беспокойства }\end{array}$ & 0.623 & -0.420 & $p<0.01$ \\
\hline $\begin{array}{l}\text { Когнитивная } \\
\text { несостоятельность }\end{array}$ & 1.191 & 1.024 & $p<0.01$ \\
\hline Контроль мыслейі & 0.421 & -0.639 & $p<0.01$ \\
\hline $\begin{array}{l}\text { Внимательность к собственным } \\
\text { мыслительным процессам }\end{array}$ & 0.098 & -0.719 & $p<0.15$ \\
\hline
\end{tabular}


Факторы англоязычной версии и включенные в них пункты

\begin{tabular}{|c|c|}
\hline Фактор & Пункты \\
\hline $\begin{array}{l}\text { Негативные } \\
\text { убеждения, } \\
\text { связанные с } \\
\text { неуправляемостью } \\
\text { и опасностью } \\
\text { беспокойства } \\
\text { (Фактор 1) }\end{array}$ & $\begin{array}{l}\text { 2) Мое волнение опасно для меня } \\
\text { 3) Тревожные мысли не исчезают, несмотря на попытки остановить их } \\
\text { 4) Беспокойством я могу довести себя до болезни, плохого } \\
\text { самочувствия } \\
\text { 11) Я не могу отвлечься от тревожных мыслей } \\
\text { 16) Мое волнение может свести меня с ума } \\
\text { 22) Если я начинаю волноваться, то я не могу остановиться }\end{array}$ \\
\hline $\begin{array}{l}\text { Контроль мыслей } \\
\text { (Фактор 2) }\end{array}$ & $\begin{array}{l}\text { 6) Если я позволю себе отвлечься от тревожных мыслей и вдруг } \\
\text { произойдет то, чего я опасаюсь, это будет по моей вине } \\
\text { 9) Я должен(должна) всегда контролировать свои мысли } \\
\text { 15) Я буду наказан за то, что не контролирую определенные мысли } \\
\text { 21) Неумение контролировать собственные мысли является } \\
\text { признаком слабости } \\
\text { 25) Некоторые мысли слишком плохие, чтобы держать их в голове } \\
\text { 27) Если я не смогу контролировать свои мысли, я не буду } \\
\text { нормально функционировать (жить) }\end{array}$ \\
\hline $\begin{array}{l}\text { Когнитивная } \\
\text { несостоятельность } \\
\text { (Фактор 3) }\end{array}$ & $\begin{array}{l}\text { 8) Я не уверен(а) в своих способностях запоминать слова и } \\
\text { названия } \\
\text { 14) Моя память не такая хорошая, порой она может ввести меня в } \\
\text { заблуждение, я часто что-то забываю } \\
\text { 18) У меня плохая память } \\
\text { 24) У меня плохая память на места } \\
\text { 26) Я не доверяю моей памяти } \\
\text { 29) У меня плохая память на события }\end{array}$ \\
\hline $\begin{array}{l}\text { Позитивные } \\
\text { убеждения, } \\
\text { касающиеся } \\
\text { беспокойства } \\
\text { (Фактор 4) }\end{array}$ & $\begin{array}{l}\text { 1) Волнение помогает мне избежать проблем в будущем } \\
\text { 7) Волнение помогает мне оставаться собранным(ой) } \\
\text { 10) Волнение помогает мне «разложить все по полочкам» } \\
\text { 20) Волнение помогает мне справляться с трудными жизненными } \\
\text { ситуациями } \\
\text { 23) Волнение помогает мне решать проблемы } \\
\text { 28) Мне нужно беспокоиться, чтобы справляться с трудностями }\end{array}$ \\
\hline $\begin{array}{l}\text { Внимательность к } \\
\text { собственным } \\
\text { мыслительным } \\
\text { процессам } \\
\text { (Фактор 5) }\end{array}$ & $\begin{array}{l}\text { 5) Я осознаю, как я мыслю, когда размышляю над решением } \\
\text { проблемы } \\
\text { 12) Я контролирую свои мысли } \\
\text { 13) Мне кажется, что я много размышляю о своих мыслях } \\
\text { 17) Я непрерывно осознаю ход своих мыслей } \\
\text { 19) Я обращаю пристальное внимание на то, как работает мой ум } \\
\text { 30) Я постоянно изучаю свои мысли }\end{array}$ \\
\hline
\end{tabular}

- критерий относительного согласия модели составил 0.93, что является высоким показателем согласованности модели;

- квадратичная усредненная ошибка аппроксимации составила 0.04, что свидетельствует о точности модели в отношении данных; 
- критерий $\chi^{2}$ составил 107 при числе степеней свободы 40, а их частное составило 2.67.

Таким образом, пятифакторная модель опросника хорошо согласуется с полученными нами данными, а англоязычные факторы могут быть использованы как шкалы русскоязычной версии опросника.

\section{Надежность-согласованность методики}

Альфа Кронбаха методики в обследованных выборках достигает высокого уровня (0.83). Анализ показателя надежности по отдельным шкалам показал, что отдельные шкалы методики имеют высокие значения альфа Кронбаха, кроме шкалы «Контроль мыслей» и шкалы «Внимательность к собственным мыслительным процессам» (достаточный уровень надежности). Анализ расщепленной надежности (критерий Гутмана) составил 0.75. Полученные результаты представлены в таблице 3 .

\section{Тест-ретестовая надежность}

Повторное тестирование проводилось через два месяца после первичного обследования. В повторном исследовании приняли участие 40 студентов, 30 респондентов,

Таблица 3

Показатели надежности краткой версии опросника метакогнитивных убеждений

\begin{tabular}{|c|c|c|c|c|}
\hline IШкалы методики & $\begin{array}{c}\alpha \\
\text { Кронбаха } \\
\text { (по всей } \\
\text { выборке) }\end{array}$ & $\begin{array}{c}\text { Студенты } \\
(\mathrm{n}=200)\end{array}$ & $\begin{array}{c}\text { Респонденты, } \\
\text { обследованные с } \\
\text { помощью интернет- } \\
\text { технологий }(\mathrm{n}=100)\end{array}$ & $\begin{array}{c}\text { Женщины с } \\
\text { онкологическими } \\
\text { заболеваниями } \\
\text { репродуктивной } \\
\text { системы }(\mathrm{n}=200)\end{array}$ \\
\hline $\begin{array}{l}\text { Позитивные } \\
\text { убеждения, } \\
\text { касающиеся } \\
\text { беспокойства }\end{array}$ & 0.82 & 0.81 & 0.82 & 0.84 \\
\hline $\begin{array}{l}\text { Негативные убеж- } \\
\text { дения, связанные с } \\
\text { неуправляемостыю } \\
\text { и опасностью } \\
\text { беспокойства }\end{array}$ & 0.83 & 0.82 & 0.80 & 0.83 \\
\hline $\begin{array}{l}\text { Когнитивная } \\
\text { несостоятельность }\end{array}$ & 0.81 & 0.81 & 0.81 & 0.81 \\
\hline Контроль мыслей & 0.76 & 0.76 & 0.78 & 0.77 \\
\hline $\begin{array}{l}\text { Внимательность } \\
\text { к собственным } \\
\text { мыслительным } \\
\text { процессам }\end{array}$ & 0.77 & 0.75 & 0.77 & 0.77 \\
\hline
\end{tabular}


обследованных с помощью интернет-технологий, 40 больных раком молочной железы. Тест-ретестовые корреляции показателей по шкалам опросника метакогнитивных убеждений варьируются от 0.55 до 0.80. Тест-ретестовые корреляции отдельных пунктов также значимо положительные и варьируются от 0.30 до 0.69 .

Полученные результаты представлены в таблице 4. Иными словами, как пункты методики, так и отдельные шкалы могут быть признаны стабильными.

\section{Социально-демографические характеристики и метакогнитивнье убеждения}

Семейное положение, а также пол не были связаны с общим уровнем выраженности дисфункциональных метакогнитивных убеждений, а также шкалами методики. Однако были выявлены статистически достоверные отрицательные корреляции возраста со шкалой «Контроль мыслей» $(r=-0.245 ; p<0.001)$, а также шкалой «Внимательность к собственным мыслительным процессам» $(r=0.316 ; p<0.001)$. Таким образом, можно предположить, что респонденты в более старшем возрасте в меньшей степени убеждены в том, что если не контролировать мысли, то может случиться чтото плохое. Кроме того, с возрастом тенденция фокусировать свое внимание на собственных мыслях также снижается.

Клинико-анамнестические характеристики и метакогнитивные убеждения женщин со злокачественными онкологшческими заболеваниями репродуктивной системь

Анализ корреляций между метакогнитивными убеждениями и клиническими характеристиками в подгруппе женщин с онкологическими заболева-

Таблииа 4

Показатели тест-ретестовой надежности краткой версии опросника метакогнитивных убеждений

\begin{tabular}{|l|c|}
\hline \multicolumn{1}{|c|}{ Шкалы методики } & $\begin{array}{c}\text { Тест-ретестовая надежность } \\
\text { (n = 110) }\end{array}$ \\
\hline Позитивные убеждения, касающиеся беспокойства & $0.80(p<0.001)$ \\
\hline $\begin{array}{l}\text { Негативные убеждения, связанные с } \\
\text { неуправляемостью и опасностью беспокойства }\end{array}$ & $0.75(p<0.001)$ \\
\hline Когнитивная несостоятельность & $0.55(p<0.001)$ \\
\hline Контроль мыслей & $0.64(p<0.001)$ \\
\hline $\begin{array}{l}\text { Внимательность к собственным мыслительным } \\
\text { процессам }\end{array}$ & $0.64(p<0.001)$ \\
\hline
\end{tabular}


ниями репродуктивной системы не выявил статистически достоверных связей.

\section{Внешняя валидность краткой версии опросника метакогнитивньх убеждений}

\section{Метакогнитивные убеждения и тревога}

Корреляционный анализ проводился с использованием критерия $r$ Спирмена. Было выявлено, что тревога статистически достоверно положительно связана со шкалой «Позитивные убеждения, касающиеся беспокойства $(r=0.456 ; p<0.01)$, шкалой «Негативные убеждения, связанные с неуправляемостью и опасностью беспокойства» $(r=0.544 ; p<0.001)$, шкалой «Контроль мыслей» $(r=0.344 ; p<0.01)$, шкалой «Внимательность к собственным мыслительным процессам» $(r=0.326 ; p<0.01)$.

Иными словами, повышение уровня тревоги сопровождается актуализацией убеждений, отражающих веру в то, что более частое беспокойство поможет избежать проблем и справиться с трудностями. В то же время рост тревоги соотносится с выраженностью негативных убеждений, связанных с неуправляемостью и опасностью беспокойства. Кроме того, выраженность тревожных переживаний соотносится с более частой тенденцией фокусировать свое внимание на собственных мыслительных процессах, думать о них, а также с потребностью в контроле мыслей.

При анализе корреляций не было выявлено статистически достоверных связей со шкалой «Когнитивная несостоятельность». Можно предположить, что люди с более высоким уровнем тревожности не склонны обращать внимание на функционирование собственной памяти, при этом для данной категории характерной является необходимость в контроле мыслительной деятельности.

\section{Метакогнитивные убеждения и депрессия}

При анализе связи депрессии и метакогнитивных убеждений было выявлено, что такие шкалы, как «Негативные убеждения, связанные с неуправляемостью и опасностью беспокойства» $(R=0.456 ; p<0.001)$, «Когнитивная несостоятельность» $(R=0.356 ; p<0.01)$, статистически достоверно положительно связаны с ростом депрессивных переживаний. Кроме того, была выявлена статистически достоверная положительная связь депрессии со шкалой «Внимательность к собственным мыслительным процессам» $(R=0.43 ; p<0.01)$. Не было выявлено статистически достоверных корреляций с такими шкалами, как «Контроль мыслей» и «Позитивные убеждения, касающиеся беспокойства».

Таким образом, рост депрессивных переживаний соотносится с актуализацией убеждений, связанных с невозможностью контроля и телесной, психологической или социальной опасностью беспокойства. 
В ряде исследований показано, что для лиц с более высоким уровнем депрессии характерной является негативная оценка собственной мнестической деятельности. Многие исследователи подчеркивают, что пациенты, страдающие от сниженного настроения, характеризуются жалобами на собственную память (Comijs et al, 2002). Такую особенность людей с депрессивными состояниями, в первую очередь, связывают с тенденцией к негативно окрашенному эмоциональному контролю и оценке своих способностей, а также с попытками контролировать автоматизированные когнитивные процессы (Crane et al., 2007).

\section{Метакогнитивные убеждения и стратегии когнитивной регуляции эмоцией}

По результатам корреляционного анализа выявлено, что со шкалой «Позитивные убеждения, касающиеся беспокойства» связана только одна стратегия когнитивной регуляции эмоций - «Катастрофизация» $(r=0.322$; $p<0.01$ ).

Шкала «Негативные убеждения, связанные с неуправляемостью и опасностью беспокойства» статистически достоверно положительно связана с такими стратегиями, как «Самообвинение» $(r=0.367 ; p<0.03)$, «Руминации» $(r=0.456, p=0.05)$, «атастрофизация» $(r=0.415 ; p<0.05)$.

Шкала «Когнитивная несостоятельность» статистически достоверно положительно связана со стратегией «Самообвинение» $(r=0.315 ; p<0.01)$. С другими стратегиями когнитивной регуляции эмоций статистически достоверных различий не выявлено.

Шкала «Контроль мыслей» статистически достоверно связана с когнитивной стратегией «Катастрофизация» $(r=0.378 ; p<0.02)$, а также со стратегией «Самообвинение» $(r=0.237 ; p<0.02)$.

Шкала «Внимательность к собственным мыслительным процессам» связана со стратегией «Руминации» $(r=0.456 ; p<0.05)$.

Таким образом, актуализация дисфункциональных метакогнитивных убеждений связана с выбором малоадаптивных стратегий эмоциональной регуляции, которые отражают персистирующие формы регуляции (например, руминации и катастрофизация, а также обвинение других), что подтверждает нашу гипотезу и согласуется с выводами зарубежных исследований.

\section{Конструктная валидность методики}

Согласно модели метакогнитивных убеждений А. УЭллса, имплицитные метакогнитивные убеждения способствуют активизации и поддержанию тревожно-депрессивных переживаний, а также способствуют выбору малоадаптивных стратегий переработки негативных переживаний.

Для оценки вклада малоадаптивных метакогнитивных убеждений в тревожно-депрессивные переживания была использована множественная линейная регрессия (метод пошагового включения переменных в регрессионную модель). 


\section{Вклад метакогнитивных убеждений в тревожные состояния}

Первая серия регрессионного анализа была направлена на анализ вклада метакогнитивных убеждений в тревожные состояния у обследованных респондентов.

А. Уэллс выдвинул гипотезу, согласно которой беспокойство поддерживается метакогнитивными убеждениями относительно преимуществ и опасности беспокойства. Первоначально беспокойство возникает как ответ на интрузивные мысли (например, «Что делать, если у меня обнаружат рак?»), которые связаны с угрозой физическому здоровью, социальному и финансовому благополучию. Такое беспокойство было обозначено как беспокойство по типу 1. Позитивные метакогнитивные убеждения отражают правила, связанные с полезностью беспокойства как стратегии выживания (например, «Тревожные мысли помогают мне справляться» или «Если я буду волноваться, то это поможет мне лучше подготовиться к возможной проблеме). А. УЭллс подчеркивает, что позитивные убеждения, касающиеся беспокойства, являются нормальными и могут наблюдаться у лиц, не имеющих клинических проявлений тревожности. Отличительная особенность людей с клинически выраженной тревогой заключается в актуализации негативных убеждений, в частности, о неуправляемости (например, «Мои тревожные мысли не уходят, несмотря на то, что я стараюсь их остановить) и опасности (например, «Тревога сведет меня с ума») беспокойства. Активация данных убеждений способствует негативной оценке беспокойства - беспокойстве о беспокойстве (метабеспокойство) или беспокойстве по типу 2. Метабеспокойство, с одной стороны, усиливает тревогу, которая может достигать уровня панических атак, с другой стороны, поддерживает убежденность в необходимости продолжать беспокойство в связи с сохраняющимся чувством опасности (Ellis, Hudson, 2010).

Множественный регрессионный анализ показал, что на уровень выраженности тревоги у обследуемых оказывают совместное влияние следующие метакогнитивные факторы: «Негативные убеждения, связанные с неуправляемостью и опасностью беспокойства», «Внимательность к собственным мыслительным процессам», а также «Позитивные убеждения, касающиеся беспокойства» $(F=22.34 ; p<0.001)$. Данная модель позволяет объяснить $23 \%$ дисперсии зависимой переменной $\left(R^{2}=0.23\right)$.

Полученные результаты представлены в таблице 5.

\section{Вклад метакогнитивных убеждений в депрессию}

Вторая серия регрессионного анализа была направлена на анализ вклада метакогнитивных убеждений в депрессивные состояния у обследованных респондентов.

Множественный регрессионный анализ показал, что на уровень выраженности тревоги у обследуемых оказывают совместное влияние следующие метакогнитивные факторы: «Негативные уб́ждения, связанные с неуправ- 
Таблица 5

Вклад метакогнитивных убеждений в общий уровень тревоги

\begin{tabular}{|l|c|c|c|c|}
\hline \multicolumn{1}{|c|}{ Зависимая переменная - Тревога } & $\boldsymbol{R}^{2}=\mathbf{0 . 2 3 3}$ & $\boldsymbol{\beta}$ & $\boldsymbol{t}$ & $\boldsymbol{p}$ \\
\hline $\begin{array}{l}\text { Негативные убеждения, связанные с неуправляемостью и } \\
\text { опасностью беспокойства }\end{array}$ & 0.325 & 5.86 & 0.001 \\
\hline Внимательность к собственным мыслительным процессам & 0.169 & 2.75 & 0.001 \\
\hline Позитивные убеждения, касающиеся беспокойства & 0.117 & 2.26 & 0.02 \\
\hline
\end{tabular}

ляемостью и опасностью беспокойства», «Когнитивная несостоятельность», «Внимательность к собственным мыслительным процессам» $(F=20.32 ; p<0.001)$. Данная модель позволяет объяснить 17\% дисперсии зависимой переменной $\left(R^{2}=0.17\right)$.

Полученные результаты представлены в таблице 6.

Выраженность депрессивных переживаний у обследованных обусловлена, в частности, наличием убеждений, отражающих оценку беспокойства как опасного и неконтролируемого. Это согласуется с рядом зарубежных исследований, в которых показано, что для лиц с депрессией характерной особенностью является «депрессивное беспокойство» (Papageorgiou, 2006). Беспокойство при депрессии рассматривается как активная когнитивная стратегия, направленная на антиципацию опасности и планирование способов ее предотвращения. В структуре депрессии беспокойство усиливает тревожные переживания пациентов, впоследствии переходящие в руминации (Segerstrom et al., 2000).

Таким образом, краткая версия опросника метакогнитивных убеждений представляет собой многомерную методику, которая позволяет исследовать пять негативных метакогнитивных факторов (негативные убеждения, связанные с неуправляемостью и опасностью беспокойства; контроль мыслей; позитивные убеждения, касающиеся беспокойства; когнитивная несостоятельность; внимательность к собственным мыслительным процессам), участвующих в развитии и поддержании эмоциональных расстройств. Представленные

Таблица 6

Вклад метакогнитивных убеждений в общий уровень депрессии

\begin{tabular}{|l|c|c|c|c|}
\hline \multicolumn{1}{|c|}{ Зависимая переменная - Депрессия } & $\boldsymbol{R}^{2}=\mathbf{0 . 1 7}$ & $\boldsymbol{\beta}$ & $\boldsymbol{t}$ & $\boldsymbol{p}$ \\
\hline $\begin{array}{l}\text { Негативные убеждения, связанные с } \\
\text { неуправляемостью и опасностью беспокойства }\end{array}$ & & 0.284 & 4.96 & 0.001 \\
\hline Когнитивная несостоятельность & & 0.187 & 3.27 & 0.001 \\
\hline $\begin{array}{l}\text { Внимательность к собственным мыслительным } \\
\text { процессам }\end{array}$ & & 0.128 & 2.40 & 0.01 \\
\hline
\end{tabular}


результаты показывают, что методика и ее шкалы имеют хорошую внутреннюю согласованность, а факторная структура согласуется с англоязычной версией опросника. Проведенный конфирматорный факторный анализ подтверждает пятифакторную структуру опросника. Внешняя валидность методики подтверждается корреляционным анализом в сопоставлении с тревогой, депрессией и стратегиями когнитивной регуляции эмоций. В соответствии с авторской моделью метакогнитивные убеждения вносят самостоятельный вклад в развитие тревожно-депрессивных переживаний.

В целом методика может применяться для диагностики дисфункциональных метакогнитивных убеждений, которые считаются важными в изучении и концептуализации психопатологических процессов при тревожных расстройствах и депрессии.

\section{Литература}

Карпов, А. В. (2004). Метасистемная организация уровневых структур психики. М.: Изд-во «Институт психологии РАН».

Плужников, И. В. (2010). Эмоциональный интеллект при аффективных расстройствах (Кандидатская диссертация). Московский государственный университет им. М.В. Ломоносова, Москва.

Рассказова, Е. И., Плужников, И. В. (2013). Психодиагностика уровня когнитивного инсайта: результаты апробации русскоязычной версии шкалы когнитивного инсайта А. Бека. Психологические исследования, 6(28), 6. Режим доступа: http://psystudy.ru

Тхостов, А. Ш., Иржевская, В. П., Рупчев, Г. Е., Морозова, М. А. (2007). Инсайт в патопсихологии (историеские, теоретическе и методологиеские аспекты). М.: Изд-во Московского университета.

Ссылки на зарубежные источники см. в разделе References после аналоязыиного блока.

Сирота Наталья Александровна - декан, факультет клинической психологии, заведующая кафедрой, кафедра клинической психологии, Московский государственный медико-стоматологический университет имени А.И. Евдокимова, доктор медицинских наук, профессор. Сфера научных интересов: копинг-поведение при различных психических, психосоматических и соматических состояниях, аддиктивное поведение.

Контакты: sirotan@mail.ru

Московченко Денис Владимирович - старший преподаватель, кафедра клинической психологии, Московский государственный медико-стоматологический университет имени А.И. Евдокимова, кандидат психологических наук.

Сфера научных интересов: механизмы психологической саморегуляции и ее нарушения при психических расстройствах, совладающее поведение.

Контакты: xedin-90@mail.ru 
Ялтонский Владимир Михайлович - профессор, кафедра клинической психологии, Московский государственный медико-стоматологический университет имени А.И.Евдокимова, доктор медицинских наук, профессор.

Сфера научных интересов: индивидуальное, семейное совладающее с болезнью и лечением поведение, психосоматика и психология телесности.

Контакты: yaltonsky@mail.ru

Ялтонская Александра Владимировна - старший научный сотрудник, ФГБУ «ФМИЦ психиатрии и наркологии имени В.П. Сербского», врач-психиатр, психотерапевт, кандидат медицинских наук.

Сфера научных интересов: хронические аффективные и тревожные расстройства, личностные расстройства.

Контакты: y_alex00@mail.ru

\title{
Approbation of the Short Version Questionnaire Metacognitive Belief in Russian-Speaking Population
}

\author{
N.A. Sirota ${ }^{a}$, D.V. Moskovchenko ${ }^{a}$, V.M. Yaltonsky ${ }^{a}$, A.V. Yaltonskaya ${ }^{b}$ \\ "A.I. Yevdokimov Moscow State University of Medicine and Dentistry, 20-1 Delegatskaya Str., Moscow, \\ 127473, Russian Federation \\ ${ }^{5}$ Serbsky Federal Medical Research Center of Psychiatry and Narcology, 37-1 Lymblinskaya Str., Moscow, \\ 109390, Russian Federation
}

\begin{abstract}
In the meta-cognitive theory by A. Wells, anxiety disorders and depression are caused by the presence of dysfunctional metacognitive beliefs. In this concept there are five key metacognitive factors that lead to development of affective disorders: Positive beliefs about worry; Negative beliefs about uncontrollability and danger of anxiety; Control of thoughts; Attention to one's own thought processes; Cognitive mistrust. The intensification of metacognitive beliefs leads to the development and maintenance of stereotyped thinking styles, such as worry and rumination, as well as constant threat monitoring and attempts to suppress unwanted thoughts. A short version of the metacognitive belief questionnaire allows one to measure individual differences in the choice of dysfunctional metacognitive beliefs. This article is dedicated to the development and validation of the short version of the questionnaire of metacognitive beliefs in the Russianspeaking population. The study involved 500 people: 200 students studying at the A.I. Evdokimov Moscow State University of Medicine and Dentistry, 100 respondents were examined using Internet technologies (electronic Google forms), also 200 women with oncological diseases of the reproductive system were assessed. The results showed that the short version of the questionnaire of metacognitive beliefs fully corresponds to the English version with respect to reliability-consistency and internal structure of the items, and is also characterized by high test-retest reliability. External validity of the technique is confirmed by significant correspondence of dysfunctional metacognitive factors with the severity of anxietydepressive experiences and the choice of maladaptive strategies for cognitive regulation of emotions. Regression analysis revealed that such metacognitive factors as negative beliefs related
\end{abstract}


to uncontrollability and danger of anxiety, attentiveness to one's own thinking processes, and positive beliefs about anxiety contribute independently to the development of anxiety. It is shown that such metacognitive factors as negative beliefs related to uncontrollability and danger of anxiety, cognitive insolvency, and attentiveness to one's own thought processes contribute to the development of depressive experiences.

Keywords: metacognitions questionnaire, metacognitive beliefs, psychometrics, positive beliefs about anxiety, negative beliefs about uncontrollability and danger of anxiety, control of thoughts, cognitive mistrust.

\section{References}

Al-Hilawani, Y. A., Easterbrooks, S. R., \& Marchant, G. J. (2002). Metacognitive ability from a theory-of-mind perspective: A cross-cultural study of students with or without hearing loss. American Annals of the Deaf, 147(4), 38-47.

Borkovec, T. D. (1985). Worry: a potentially valuable concept. Behaviour Research and Therapy, 23, 481-482.

Brown, A. L. (1987). Metacognition, executive control, self-regulation and other even more mysterious mechanisms. In F. E. Weinert \& R. H. Kluwe (Eds.), Metacognition, motivation, and understanding (pp. 65-116). Hillsdale, NJ: Lawrence Erlbaum.

Cartwright-Hatton, S., \& Wells, A. (1997). Beliefs about worry and intrusions: the metacognitions questionnaire and its correlates. Joumal of Anxiety Disorders, 11, 279-296.

Comijs, H. C., Deeg, D. J., Dik, M. G., Twisk, J. W. R., \& Jonker, C. (2002). Memory complaints: The association with psycho-affective and health problems and the role of personality characteristics. A 6-year follow-up study. Joumal of Affective Disorders, 72, 157-166.

Crane, M. K., Bogner, H. R., Brown, G. K., \& Gallo, J. J. (2007). The link between depressive symptoms, negative cognitive bias and memory complaints in older adults. Aging and Mental Health, 11, $708-715$.

Cross, D. R., \& Paris, S. G. (1988). Developmental and instructional analyses of children's metacognition and reading comprehension. Journal of Educational Psychology, 80(2), 131-142.

Ellis, D. M., \& Hudson, J. L. (2010). The metacognitive model of generalized anxiety disorder in children and adolescents. Clinical Child and Family Psychology Reriew, 13(2), 151-163.

Fisher, P., \& Wells, A. (2009). Metacognitive therapy: Distinctive features (CBT Distinctive Features). London/New York: Routledge.

Flavell, J. H. (1979). Metacognition and cognitive monitoring: A new area of cognitive-developmental inquiry. American Psychologist, 34(10), 906-911.

Flavell, J. H. (1999). Cognitive development: Children's knowledge about the mind. Anmual Reviere of Psychology, 50, 21-45.

Garnefski, N., Kraaij, V., \& Spinhoven, P. (2001). Negative life events, cognitive emotion regulation and emotional problems. Personality and Individual Differences, 30, 1311-1327.

Karpov, A. V. (2004) Metasistemnaya organizatsiya uroznezykh struktur psikhiki [Metasystem organization tier structure of the mind]. Moscow: Institute of Psychology of RAS. (in Russian)

Kuhn, D., \& Dean, D. (2004). Metacognition: A bridge between cognitive psychology and educational practice. Theory into Practice, 43(4), 268-273. 
Newby, J., Williams, A., Andrews, G. (2014). Reductions in negative repetitive thinking and metacognitive beliefs during transdiagnostic internet cognitive behavioural therapy (iCBT) for mixed anxiety and depression. Behav Res Ther., 59, 52-60.

Nolen-Hoeksema, S. (2004). The response styles theory. In C. Papageorgiou \& A. Wells (Eds.), Depressive rumination: Nature, theory, and treatment (pp. 107-124). New York: Wiley.

Papageorgiou, C. (2006). Worry and rumination: Styles of persistent negative thinking in anxiety and depression. In G. C. L. Davey \& A. Wells (Eds.), Worry and its psychological disorders: Theory, assessment and treatment (pp. 21-40). Hoboken, NJ: Wiley Publishing.

Papageorgiou, C., \& Wells, A. (2001). Metacognitive beliefs about rumination in recurrent major depression. Cognitive and Behavioral Practice, 8, 160-164.

Papaleontiou-Louca, E. (2003). The concept and instruction of metacognition. Teacher Development, $7(1), 9-30$.

Pluzhnikov, I. V. (2010). Emotsional'nyy intellekt pri affektivnykh rasstroistvakh [Emotional intelligence in affective disorders] (PhD dissertation). Lomonosov Moscow State University, Moscow, Russian Federation. (in Russian)

Rasskazova, E. I., \& Pluzhnikov, I. V. (2013). Psychodiagnostics of cognitive insight: the results of trying and testing the Russian version of the Beck Cognitive Insight Scale. Psikhologicheskiye Issledovaniya, 6(28), 6. Retrieved from http://psystudy.ru (in Russian)

Segerstrom, S. C., Tsao, J. C. I., Alden, L. E., \& Craske, M. G. (2000). Worry and rumination: Repetitive thought as a concomitant and predictor of negative mood. Cognitive Therapy and Research, 24, 671-688.

Tkhostov, A. S., Irzhevskaya, V. P., Rupchev, G. E., \& Morozova, M. A. (2007). Insait v patopsikhologii (istoricheskie, teoreticheskie i metodologicheskie aspekty) [Insight in psychopathology (historical, theoretical and methodological aspects)]. Moscow: Moscow State University Press. (in Russian)

Wells, A. (2000). Emotional disorders and metacognition: Innovative cognitive therapy. Chichester, UK: John Wiley \& Sons.

Wells, A. (2002). GAD, metacognition, and mindfulness: An information processing analysis. Clinical Psychology: Science and Practice, 9(1), 95-100.

Wells, A., \& Carter, K. (2001). Further tests of a cognitive model of generalized anxiety disorder: Metacognitions and worry in GAD, panic disorder, social phobia, depression, and nonpatients. Behavior Therapy, 32, 85-102.

Wells, A., Cartwright-Hatton, S. (2004). A short form of the metacognitions questionnaire: properties of the MCQ-30. Behaviour Research and Therapy, 4, 385-395.

Wells, A., \& Papageorgiou, C. (1998). Relationships between worry, obsessive-compulsive symptoms and meta-cognitive beliefs. Behaviour Research and Therapy, 36, 899-913.

Zigmond, A. S., \& Snaith, R. P. (1983). The hospital anxiety and depression scale. Acta Psychiatrica Scandinavica, 67(6), 361-370.

Natalya A. Sirota - dean, Department of Clinical Psychology, head, Chair of Clinical Psychology, A.I. Yevdokimov Moscow State University of Medicine and Dentistry, M.D., professor.

Research area: coping behavior in different psychiatric, psychosomatic and physical conditions, addictive behavior.

E-mail: sirotan@mail.ru 
Denis V. Moskovchenko - senior lecturer, Department of Clinical Psychology, A.I. Yevdokimov Moscow State University of Medicine and Dentistry, Ph.D.

Research area: mechanisms of psychological self-regulation in mental disorders, coping behavior. E-mail: xedin-90@mail.ru

Vladimir M. Yaltonsky - professor, A.I. Yevdokimov Moscow State University of Medicine and Dentistry, M.D., professor.

Research area: individual and family coping with illness and treatment behavior, psychotherapy and prevention of dependent behavior, psychosomatics.

E-mail: yaltonsky@mail.ru

Aleksandra V. Yaltonskaya - senior research associate, Serbsky Federal Medical Research Center of Psychiatry and Narcology, psychiatrist, psychotherapist, Ph.D.

Research area: chronic mood and affective disorders, personality disorders.

E-mail: yaltonskayaa@gmail.com 